\title{
Medial compartment disease in a young Large Munsterlander
}

\author{
Medial compartment disease bij een jonge grote münsterländer
}

\author{
E.Coppieters, Y. Samoy, P. Pey, T. Waelbers, B. Van Ryssen
}

Department of Veterinary Medical Imaging and Small Animals Orthopedics, Faculty of veterinary medicine, Ghent University, Salisburylaan 133, B-9820 Merelbeke Belgium

eva.coppieters@ugent.be

\begin{abstract}
Medial compartment disease (MCD) is a recently recognized elbow disorder in dogs and refers to extensive cartilage erosions of the medial compartment of the elbow joint. This report describes a case of MCD in a 10month-old Large Munsterlander that was presented with right frontleg lameness. Based on signalement, history and radiographic examination, there was a strong suspicion of a fragmented coronoid process (FCP) of the right elbow. However, arthroscopic examination revealed extensive cartilage erosions of the medial part of the humeral condyle and the medial coronoid process in addition to a small coronoid fragment (FCP) and a small OCD-like lesion. After the arthroscopic treatment, the dog did not improve. Neither did additional treatment with autologous conditioned plasma (Arthrex ACPÒ) lead to a substantial improvement. Finally, the dog was euthanized because of persistent lameness.
\end{abstract}

\section{SAMENVATTING}

Medial Compartment Disease (MCD) is een recent herkende aandoening van de elleboog bij de hond en verwijst naar uitgebreide kraakbeenerosies in het mediaal gedeelte van het ellebooggewricht. Deze casuïstiek beschrijft een geval van MCD bij een grote münsterländer van tien maanden oud, aangeboden met de klacht van manken op de rechtervoorpoot. Op basis van het signalement, de anamnese en het radiografisch onderzoek, was er een sterk vermoeden van een losse processus coronoïdeus van de rechterelleboog. Artroscopische inspectie van het gewricht bracht echter naast een klein coronoïdfragment en een klein osteochondrotisch letsel, ook uitgebreide kraakbeenerosies van de mediale humeruscondyl en de mediale processus coronoïdeus aan het licht. $\mathrm{Na}$ de artroscopische behandeling vertoonde de hond geen beterschap. Een behandeling met autoloog geconditioneerd plasma (Arthrex- ACP ${ }^{\circ}$ ) gaf evenmin substantiële verbetering. Uiteindelijk werd de hond geëuthanaseerd omwille van aanhoudend manken.

\section{INTRODUCTION}

Forelimb lameness in dogs is often caused by elbow dysplasia, a polygenic, hereditary, developmental disease that is commonly diagnosed in young large breed dogs (Morgan et al., 2003; Samoy et al., 2011b). The term elbow dysplasia includes four disorders of the elbow: fragmented coronoid process (FCP), ununited anconeal process (UAP), osteochondritis dissecans of the medial part of the humeral condyle (OCD) and elbow incongruity (Hazewinkel, 2002). With the introduction of canine arthroscopy, an unrecognized elbow problem has recently been identified in the dog, named medial compartment disease (MCD) referring to the extensive cartilage erosions of the medial compartment of the elbow joint (Vermote et al., 2010). Medial compartment disease should not be confused with medial coronoid disease, a term which has recently been introduced to indicate lesions of the medial coronoid process but in a more comprehensive way.

Until now little is known about MCD. The disease has been described as an exclusive finding in older dogs or in combination with an osteochondral fragment of the medial coronoid process (Vermote et al., 2010). It $\mathrm{s}$ also noticed in dogs with recurring lameness after an arthroscopic treatment of elbow dysplasia (Seghers et al., 2010). The cause of MCD is unknown. Abnormal forces, for example caused by elbow incongruity, acting on normal cartilage or normal forces acting on diseased cartilage of the medial aspect of the elbow joint might be the cause of MCD (Fitzpatrick et al., 2009a, Vermote et al., 2010).

Since visualization of cartilage by means of radiography, CT or MRI is not possible in dogs (De Rycke et al., 2002; Janach et al., 2006), the diagnosis of MCD is not evident. Detailed information about the cartilage can only be obtained via direct arthroscopic visualization (van Bree and Van Ryssen, 1998).

At present, no efficacious treatment has been described for MCD. A recent study describes a sliding humeral osteotomy for the treatment of MCD in the canine elbow but it is still in the experimental phase 
(Fitzpatrick et al., 2009b). In human medicine, several techniques based on tissue-engineering, the introduction of new matrices, the use of stem cells or gene therapy, are proposed to stimulate cartilage regeneration. However, none of these techniques result in a complete repair of the articular cartilage, especially when a large surface is involved (Hunziker, 2009). Cartilage damage is irreversible, which limits the treatment options to relieve the symptoms.

\section{CASE REPORT}

\section{History}

A 10-month-old, male Large Munsterlander was presented with lameness of the right forelimb for already five months. According to the owner, the lameness started bilaterally, but progressed to right forelimb lameness. The dog was first diagnosed with panosteitis by the local veterinarian and was treated with meloxicam (Metacam $\AA$, Boehringer Ingelheim Vetmedica) during two weeks. This resulted in a temporary improvement. The dog was meant to become a sporting dog.
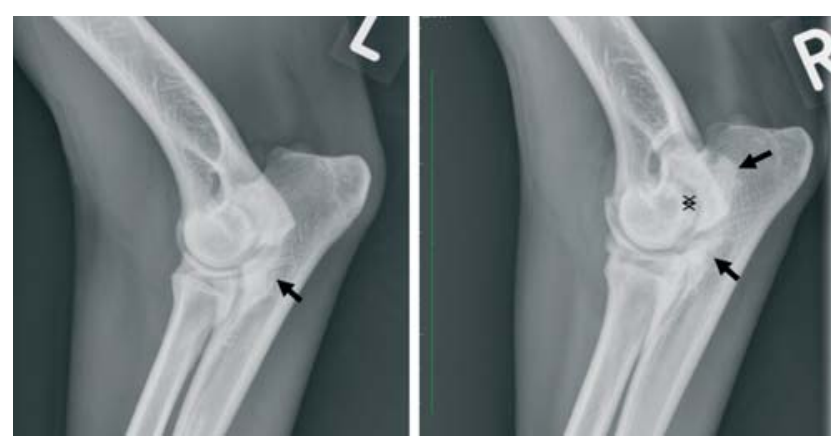

Figure 1. Radiography of both elbow joints: mediolateral extension view. Left elbow (L): mild radiolucency of the medial coronoid process and moderate osteosclerosis (arrow). Right elbow (R): radiolucent and irregular medial coronoid process and severe osteosclerosis (arrows). Increased width of the joint space at the level of the ulnar trochlear notch (double-headed arrow), indicative for mild incongruity of the elbow joint.
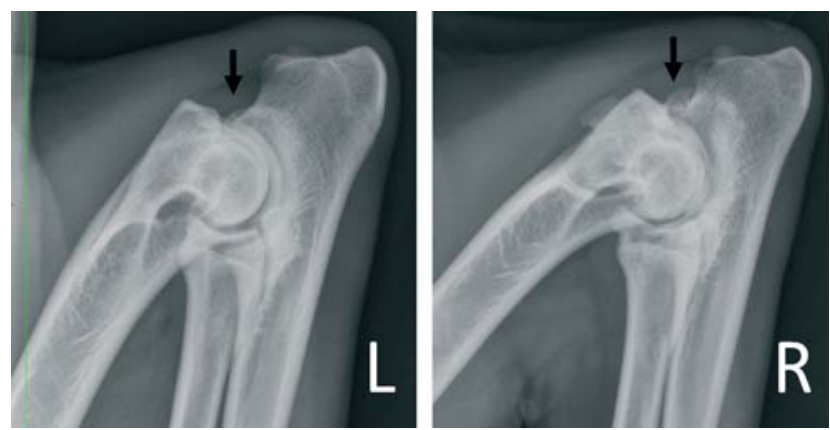

Figure 2. Radiography of both elbow joints: mediolateral flexion view. Left elbow (L): small amount of new bone formation at the anconeal process (arrow). Right albow $(R)$ : large amount of new bone formation at the anconeal process (arrow) and at the cranial part of the radial head.

\section{Clinical findings}

At presentation, moderate lameness of the right forelimb was observed at walk and trot. On orthopedic examination, there was moderate atrophy of the right shoulder muscles and moderate joint effusion of the right elbow. The range of motion was limited and flexion and extension were painful. The left elbow was slightly distended with no further abnormalities. The flexion test was positive for the right elbow.

\section{Diagnostic imaging}

Three radiographic projections (mediolateral extended view, mediolateral flexed view and craniocaudal view) of both elbows were made (Figures 1, 2, 3). The left medial coronoid process was slightly radiolucent. There was moderate osteosclerosis at the level of the ulnar trochlear notch and a small amount of solid and smooth new bone formation dorsally to the anconeal process was noticeable. In the right elbow, the medial coronoid process was markedly radiolucent and irregularly outlined. There was severe osteosclerosis at the level of the ulnar trochlear notch and a fairly large amount of solid and smooth new bone formation dorsal to the anconeal process was noticeable. On the craniocaudal view of the right elbow, a large osteophyte was visible at the medial side of the elbow, and the medial part of the humeral condyle had a flattened aspect. There was a suspicion of FCP with mild osteoarthritis of the left elbow and FCP/OCD with marked osteoarthritis of the right elbow. A CT-scan was not performed because of the strong suspicion of FCP/OCD based on clinical and radiographic examination.

\section{Treatment}

Arthroscopy of both elbows was performed via a medial approach of the joints (Van Ryssen et al., 1993). Inspection of the right elbow revealed moderate synovitis, mild incongruity and smooth white cartilage in the lateral part of the joint. Pathologic findings
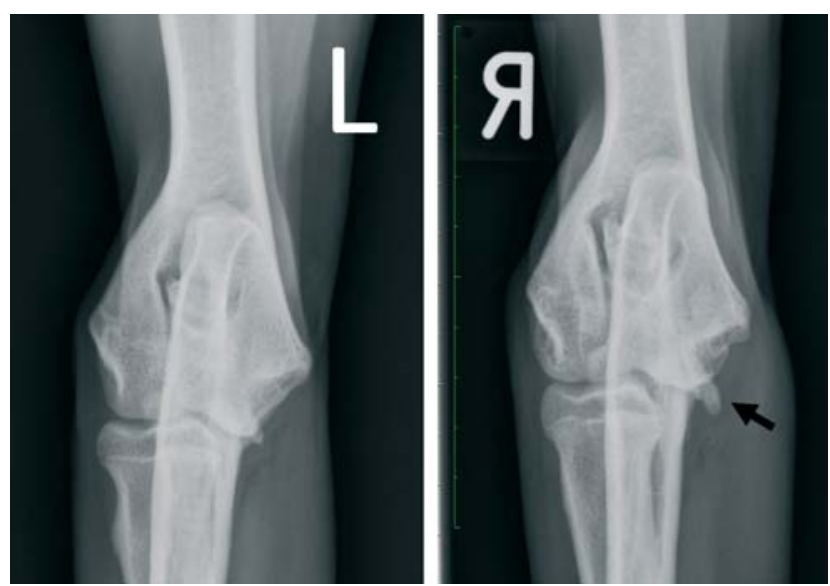

Figure 3. Radiography of both elbow joints: craniocaudal view. The right elbow shows an osteophyte (arrow) and flattening of the medial part of the humeral condyle. 

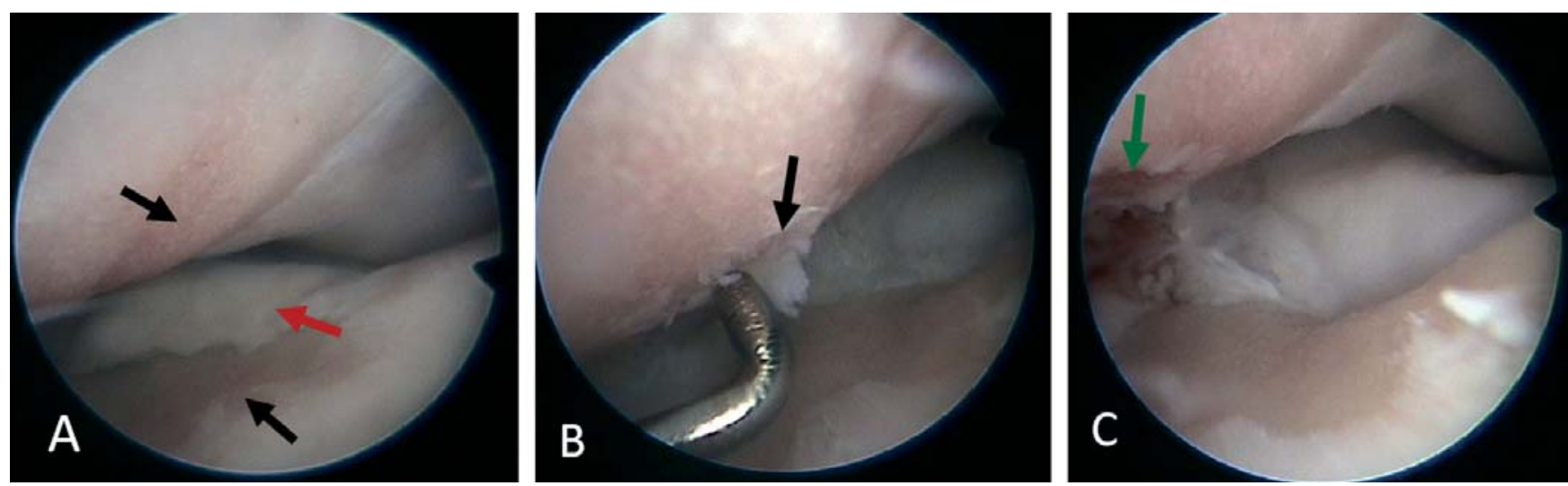

Figure 4. Arthroscopic image of the right elbow (A): severe erosions (black arrows) of the cartilage of the medial coronoid process and the medial part of the humeral condyle. There is a fragment of the medial coronoid process $(5 \times 3 \mathrm{~mm})$ (red arrow). (B): OCD-like lesion of the medial part of the humeral condyle (black arrow). The fibrocartilagenous flap is released with a probe of $1 \mathrm{~mm}$ diameter. $(\mathrm{C})$ : end result after removal of the fragment and the flap leaving bleeding subchondral bone (green arrow).

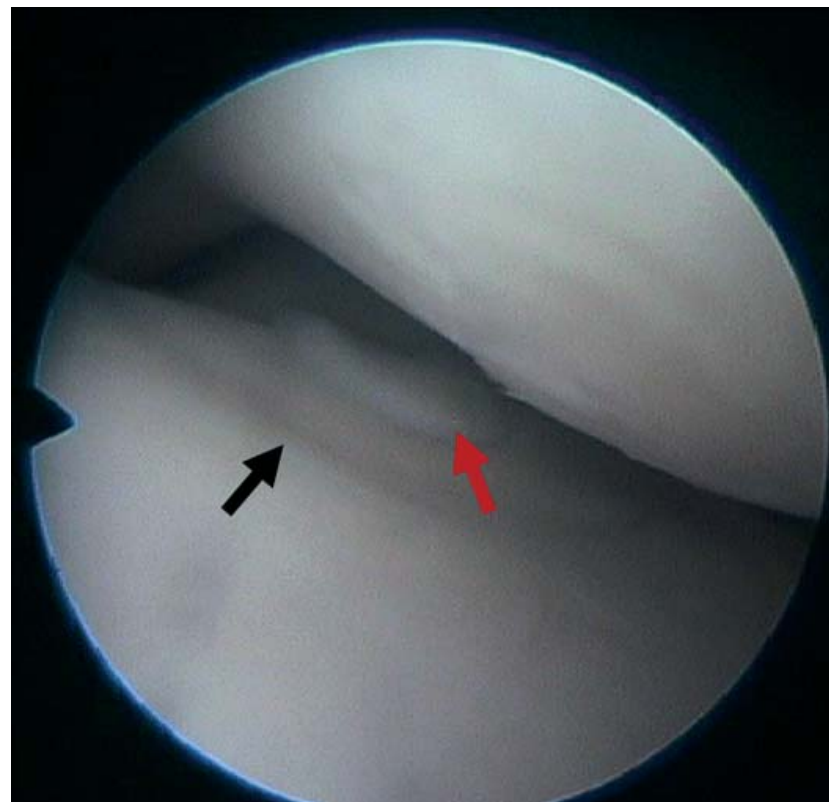

Figure 5. Arthroscopic image of the left elbow. Fissure of the medial coronoid process (black arrow) and a small, not displaced fragment (red arrow). There is mild incongruity, illustrated by the slightly lower level of the radial head.

of the medial coronoid process were a small, slightly elevated osteochondral fragment $(5 \times 3 \mathrm{~mm})$ and erosion of the cranial part of the medial coronoid process (Figure 4a). Pathologic findings of the medial aspect of the humeral condyle were a small fibrocartilagenous flap $(3 \times 3 \mathrm{~mm})$ and complete erosion of the medial part of the humeral condyle. There was a sharp delineation between the lateral and the medial joint space (Figure $4 \mathrm{~b})$. The coronoid fragment was removed with a hand burr, curette and grasping forceps ( $2 \mathrm{~mm}$ diameter instruments, R. Wolf, Knittlingen, Germany). The fibrocartilagenous flap was removed and the subchondral bone was curetted until a bleeding surface appeared (Figure 4c). Arthroscopy of the left elbow revealed mild synovitis and a non-displaced medial coronoidal fragment surrounded by a fissure (Figure 5). The car-
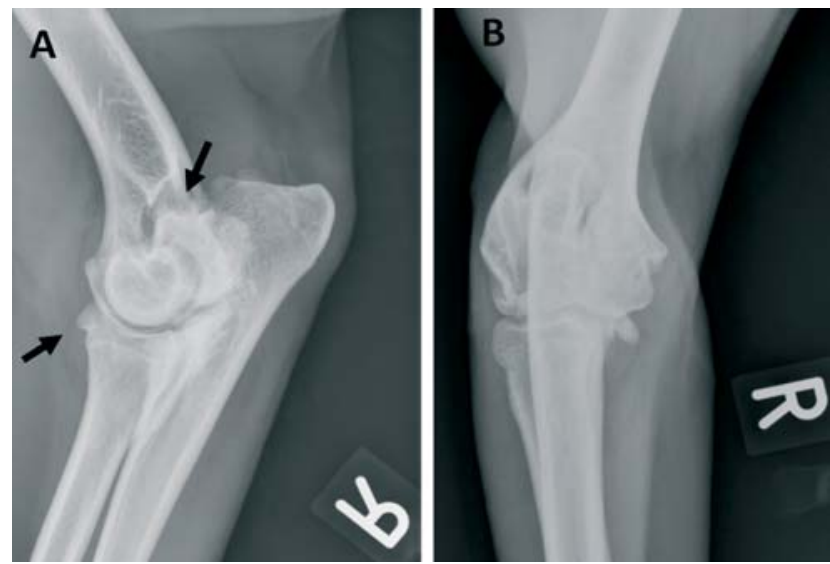

Figure 6. Radiography of the right elbow joint: mediolateral extension (A) and craniocaudal view (B), five months after arthroscopic treatment and three months after ACP treatment: a mild increase of the osteoarthritis is visible (arrows).

tilage of the medial aspect of the humeral condyle was slightly fibrillated and the joint was mildly incongruent. The left elbow was not treated because of the discrete lesions combined with minimal clinical and radiographic signs.

Postoperative treatment consisted of the administration of carprofen for a period of three weeks (Rimadyl ${ }^{\circledR}$, Pfizer A.H.) $(4 \mathrm{mg} / \mathrm{kg}$ p.o. during one week and $2 \mathrm{mg} / \mathrm{kg}$ p.o. during two weeks) and restricted movement (only walking on the leash) during six weeks.

\section{Follow-up}

Six weeks later, the lameness had not improved and a second treatment with carprofen (Rimadyl ${ }^{\circledR}$, Pfizer A.H.) was started without success. Eight weeks postoperatively, a treatment with autologous conditioned plasma (Arthrex ACPÒ) was started. The treatment consisted of four intra-articular injections weekly. Although temporary improvement was noticed in the 
first following weeks and although radiographic examination only showed a mild increase of osteoarthritis (Figure 6), the dog was euthanized because of severe persistent lameness after exercise. Permission for necropsy could not be asked since euthanasia was performed in another hospital.

\section{DISCUSSION}

This report describes a case of MCD in a young dog with a small fragment of the medial coronoid process. Until now, MCD has only been reported in chronic elbow osteoarthritis caused by large coronoid fragments, in old dogs and in dogs with recurrent lameness after surgical treatment of FCP (Seghers et al., 2010; Vermote et al., 2010).

Initially, the diagnosis of a fragmented coronoid process was made, based on the history and on the clinical and radiographic signs. Although elbow dysplasia has not been described in the Large Munsterlander and although screening is not included in the breeding guidelines, an internet search revealed that the problem has been recognized by some breeders. The clinical and radiographic signs in the present case were indicative of a fragmented coronoid process. Since radiography does not allow the visualization of cartilage, the lesions found at arthroscopy were quite surprising. The rather small coronoid fragment is not unusual as a cause of lameness, but the combination with the severe cartilage erosions of the medial compartment in this young dog is exceptional. Additionally, the small OCD-like lesion of the medial part of the humeral condyle was a rare lesion, of which the origin or exact nature cannot be explained by the authors. In contrast, typical lesions were seen in the contralateral elbow: a small fragment surrounded by a fissure of the medial coronoid process and intact cartilage in the entire joint. It should be noted that the small fragment within the fissured area was an uncommon, yet known 'double lesion' of the medial coronoid process, probably caused by multiple microfractures in the subchondral bone evolving to this 'double lesion' (B. Van Ryssen, personal communication, 2011).

The extensive cartilage erosions of the medial compartment with an intact lateral compartment are typical of MCD. Since the medial coronoid fragment was rather small, other reasons for the development of the erosions had to be considered. One reason might be the fact that the dog was already lame for as long as five months. However, many dogs are lame for a long period of time before treatment without necessarily showing severe cartilage lesions. Severe incongruity of the elbow may have caused overload of the medial compartment. However, in a report on severely incongruent elbow joints, extensive erosions were not a common finding (Samoy et al., 2011a). Furthermore, the incongruity of the joint was only moderate in the affected joint and signs typically found in severely incongruent joints, such as an irregular radio-ulnar transition, an irregular surface of the radial head or irregular cartilage in the centre of the ulnar trochlear notch, were not observed (Samoy et al., 2011a). In the present case, the evaluation of the incongruity was only based on the arthroscopic findings. However, it is known that arthroscopy is a reliable technique to evaluate incongruity (Wagner et al., 2007). Considering all factors, a clear reason for the extensive erosions could not be found. Probably, a combination of activity, the duration of the problem and unidentified causes of overload can explain the development of medial compartment disease in this young dog.

Treatment of the right elbow consisted of the arthroscopic removal of the coronoid fragment and OCD-like lesion until bleeding subchondral bone was evident. The eroded areas of the medial coronoid process and medial part of the humeral condyle were left untreated as there is no adequate treatment method for large cartilage defects yet (Hunziker et al., 2009). Techniques to support the cartilage regeneration, such as microfracturing, were not applied in this case because these techniques are mainly useful in small cartilage defects surrounded by normal cartilage (Steinwachs et al., 2008). Treatment of the contralateral elbow was not performed because of the absence of lameness and the limited clinical and radiographic changes. Although a bilateral treatment can be considered ideal, it is known that treatment does not necessarily stop the development of osteoarthritis and cartilage degeneration. On the contrary, it might induce those lesions (Seghers et al., 2010).

Despite the arthroscopic treatment and application of NSAID's and Arthrex ACP ${ }^{\circledR}$, the dog did not improve significantly. Radiographs taken five months postoperatively showed an increase of osteoarthritis, though not in an excessive way. The use of Arthrex ACPO in dogs is still under research and exact indications in canine joint diseases are not known yet. Severely degenerated joints do probably not respond sufficiently when extensive erosions are present. Considering the severe cartilage lesions, the poor prognosis could have been expected in the present case,.

Other treatment options for these extensive cartilage lesions in the elbow joint are an arthrodesis of the elbow joint or a total elbow arthroplasty. These are technically difficult surgical procedures to perform and most dogs retain an abnormal gait (Dyce, 1996; Conzemius, 2009). A proximal ulnar osteotomy has also been suggested as a treatment for medial compartment disease (Olivieri, 2010). Since the dog was meant to be used as a sporting dog, the prognosis of these surgical techniques was reserved and therefore the owners preferred no extra surgery.

The aim of this case report was to draw the attention to the fact that MCD can also be diagnosed in young dogs suspected of medial coronoid lesions. The extensive cartilage lesions have a strong negative impact on the prognosis, about which the owner should be informed. However, cartilage erosions are hard to visualize radiographically and thus can only be demonstrated by direct arthroscopic inspection at the time of treatment. It is therefore advisable to mention the possible presence of severe lesions in every case before 
treatment is performed. After diagnosing medial compartment disease, the owner should be informed about the possible poor outcome and the lack of adequate treatment.

\section{REFERENCES}

Conezmius M. (2009). Nonconstrained elbow replacement in dogs. Veterinary Surgery 38, 279-284.

De Rycke L., Gielen I., Van Bree H., Simoens P. (2002). Computed tomography of the elbow joint in clinically normal dogs. American Journal of Veterinary Research 63, 1400-1407.

Dyce J. (1996). Arthrodesis in the dog. In Practice 18, $267-$ 279.

Fitzpatrick N., Smith T., Evans R., Yeadon R. (2009a). Radiographic and arthroscopic findings in the elbow joints of 263 dogs with medial coronoid disease. Veterinary Surgery 38, 213-223.

Fitzpatrick N., Yeadon R., Smith T., Schulz K. (2009b). Techniques of application and initial clinical experience with sliding humeral osteotomy for treatment of medial compartment disease of the canine elbow. Veterinary Surgery 38(2), 261-278.

Hazewinkel H. (2002). The clinical diagnosis of elbow dysplasia. In: Proceedings 13th Annual Meeting IEWG. Granada, Spain.

Hunziker EB. (2009). The elusive path to cartilage regeneration. Advanced Materials 21(32-33), 3419-3424.

Janach K., Breit S., Kunzel W. (2006). Assessment of the geometry of the cubital (elbow) joint of dogs by use of magnetic resonance imaging. American Journal of Veterinary Research 67, 211-218.

Morgan J., Wind A., Davidson A. (2003). Elbow dysplasia. In: Hereditary Bone and Joint Diseases. Hanover: Manson Publishing Ltd,. p. 41-94.

Olivieri M. (2010). Clinical experience about treatment of medial compartment disease with proximal ulnar osteotomy. World Veterinary Orthopaedic Congress. Bologna (Italy) p. 369.
Samoy Y VVD, Gielen I, van Bree H, Duchateau L, Van Ryssen B. (2011a). Arthroscopic findings in 32 joints affected by severe elbow incongruity with concomitant fragmented medial coronoid process. Veterinary Surgery, in press.

Samoy Y, Gielen I, van Bree H, Van Ryssen B (2011b). Dysplastic elbow diseases in dogs. Vlaams Diergeneeskundig Tijdschrift 80, 327 -338.

Seghers H, De Bakker E, Van Vynckt D, Samoy Y, Diels S, Gielen I, Saunders J., van Bree H., B. Van Ryssen (2010). Lameness after arthroscopic treatment of FCP: diagnostic findings in 35 dogs. World Veterinary Orthopaedic Congress. Bologna, Italy.

Steinwachs M, Guggi T, Kreuz P (2008). Marrow stimulation techniques. Injury-International Journal of the Care of the Injured 39, S26-S31.

van Bree HJ, Van Ryssen B. (1998). Diagnostic and surgical arthroscopy in osteochondrosis lesions. Veterinary Clinics of North AmericaSmall Animal Practice 28(1), 161-89.

Vermote KA, Bergenhuyzen AL, Gielen I, van Bree H, Duchateau L, Van Ryssen B. (2010). Elbow lameness in dogs of six years and older. Veterinary and Comparative Orthopaedics and Traumatology 23, 43-50.

Van Ryssen B, vanBree H, Simoens P. (1993). Elbow arthroscopy in clinically normal dogs. American Journal of Veterinary Research 54, 191-198.

Wagner K, Griffon D., Thomas M., Schaeffer D., Schulz K, Samii V. (2007). Radiographic, computed tomographic, and arthroscopic evaluation of experimental radio-ulnar incongruence in the dog. Veterinary Surgery 36(7), 691-698. 